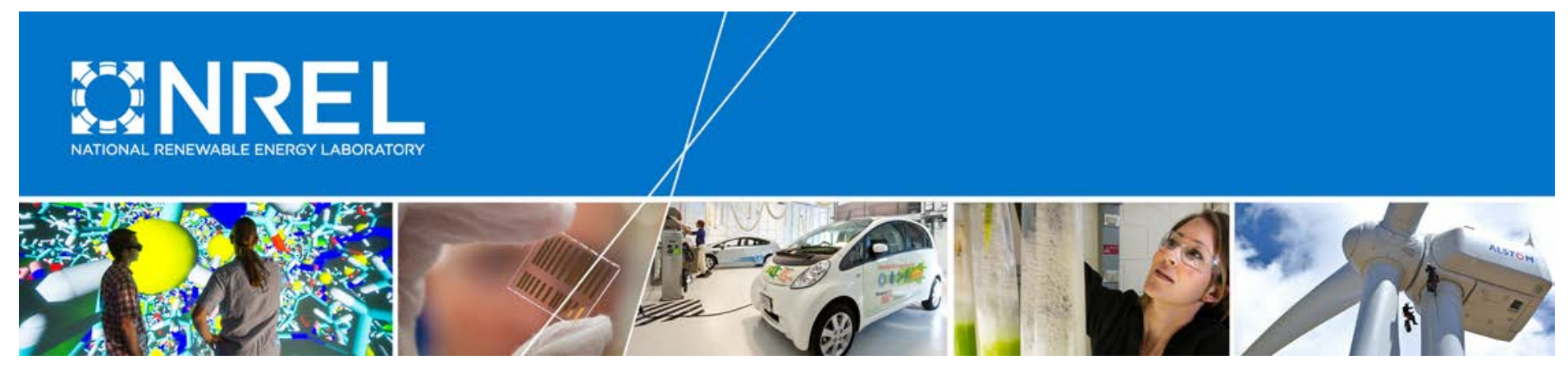

\title{
Defining Threshold Values of Encapsulant and Backsheet Adhesion for PV Module Reliability
}

\section{Preprint}

\author{
Nick Bosco, Joshua Eafanti, and Sarah Kurtz \\ National Renewable Energy Laboratory \\ Jared Tracy and Reinhold Dauskardt \\ Stanford University \\ Presented at the 2017 IEEE 44th Photovoltaic Specialists \\ Conference (PVSC) \\ Washington, $D C$ \\ June 25-30, 2017
}

(C) 2017 IEEE. Personal use of this material is permitted. Permission from IEEE must be obtained for all other uses, in any current or future media, including reprinting/republishing this material for advertising or promotional purposes, creating new collective works, for resale or redistribution to servers or lists, or reuse of any copyrighted component of this work in other works.

NREL is a national laboratory of the U.S. Department of Energy Office of Energy Efficiency \& Renewable Energy Operated by the Alliance for Sustainable Energy, LLC

This report is available at no cost from the National Renewable Energy Laboratory (NREL) at www.nrel.gov/publications.

\section{Conference Paper}

NREL/CP-5J00-67767

August 2017

Contract No. DE-AC36-08G028308 


\section{NOTICE}

The submitted manuscript has been offered by an employee of the Alliance for Sustainable Energy, LLC (Alliance), a contractor of the US Government under Contract No. DE-AC36-08GO28308. Accordingly, the US Government and Alliance retain a nonexclusive royalty-free license to publish or reproduce the published form of this contribution, or allow others to do so, for US Government purposes.

This report was prepared as an account of work sponsored by an agency of the United States government. Neither the United States government nor any agency thereof, nor any of their employees, makes any warranty, express or implied, or assumes any legal liability or responsibility for the accuracy, completeness, or usefulness of any information, apparatus, product, or process disclosed, or represents that its use would not infringe privately owned rights. Reference herein to any specific commercial product, process, or service by trade name, trademark, manufacturer, or otherwise does not necessarily constitute or imply its endorsement, recommendation, or favoring by the United States government or any agency thereof. The views and opinions of authors expressed herein do not necessarily state or reflect those of the United States government or any agency thereof.

This report is available at no cost from the National Renewable Energy Laboratory (NREL) at www.nrel.gov/publications.

Available electronically at SciTech Connect http:/www.osti.gov/scitech

Available for a processing fee to U.S. Department of Energy and its contractors, in paper, from:

U.S. Department of Energy

Office of Scientific and Technical Information

P.O. Box 62

Oak Ridge, TN 37831-0062

OSTI http://www.osti.gov

Phone: 865.576.8401

Fax: 865.576.5728

Email: reports@osti.gov

Available for sale to the public, in paper, from:

U.S. Department of Commerce

National Technical Information Service

5301 Shawnee Road

Alexandria, VA 22312

NTIS http://www.ntis.gov

Phone: 800.553 .6847 or 703.605 .6000

Fax: 703.605.6900

Email: orders@ntis.gov 


\title{
Defining Threshold Values of Encapsulant and Backsheet Adhesion for PV Module Reliability
}

\author{
Nick Bosco ${ }^{1}$, Joshua Eafanti ${ }^{1}$ and Sarah Kurtz ${ }^{1}$ \\ ${ }^{1}$ National Renewable Energy Laboratory, Golden Colorado USA \\ Jared Tracy ${ }^{2}$ and Reinhold Dauskardt ${ }^{2}$ \\ ${ }^{2}$ Stanford University, Stanford California USA
}

\begin{abstract}
The width-tapered cantilever beam method is used to quantify the debond energy (adhesion) of encapsulant and backsheet structures of $\mathbf{3 2}$ modules collected from the field. The collected population of modules contains both those that have remained intact and those with instances of either or both encapsulant and backsheet delamination. From this survey, initial threshold values (an adhesion value above which a module should remain intact throughout its lifetime) for encapsulant and backsheet interfaces are proposed. For encapsulants this value is $\sim 160 \mathrm{~J} / \mathrm{m}^{2}$ and for backsheets $\sim 10 \mathrm{~J} / \mathrm{m}^{2}$. It is expected that these values will continue to be refined and evolve as the width-tapered cantilever beam method becomes adopted by the PV industry, and that they may aid in the future improvement of accelerated lifetime tests and the development of new, low-cost materials.
\end{abstract}

\section{INTRODUCTION}

The method of quantifying the critical strain energy release rate, or debond energy, (material property of adhesion) of encapsulant and backsheet interfaces has only recently been applied within the PV industry [1-6]. Consequently, values of adhesion adequate to avoid delamination in the field have not been established. These threshold values of adhesion (an adhesion value above which a module should remain intact throughout its lifetime) are required to improve accelerated lifetime tests and for the development of new, low-cost materials.

In this paper we apply the recently developed width-tapered beam metrology to quantify adhesion of the encapsulant and backsheet interfaces of modules that have been deployed in the field between two and 27 years [3]. The modules obtained for this study are all crystalline silicon and represent both modules that have remained intact and those that exhibit either or both encapsulant and backsheet delamination. This sampling of modules will allow us to narrow the threshold of adhesion these materials must maintain to remain durable and exhibit high reliability throughout their lifetime.

\section{METHODS AND MATERIALS}

\section{A. Module Collection}

Flat plate, one-sun, crystalline silicon photovoltaic modules were collected from various sources with deployment histories between two and 27 years. A detailed list of each module type and its deployment is presented in Table I (a). Upon obtaining each module they were visually examined for pre-existing signs of delamination. Both the front encapsulant and backsheet interfaces were examined and delamination observations noted, Table I (b). These initial observations are critical for narrowing a threshold value of adhesion.

\section{B. Adhesion Measurement}

The width-tapered cantilever beam method was used to measure the adhesion of all interfaces of interest. This method of sample preparation and testing has been previously presented and is included here for clarity [3]. The metrology employs an elastic width-tapered cantilever beam adhered to the layered structure of interest. When the beam is loaded at its apex, delamination will initiate at the weakest interface and advance upon continued loading. The displacement of the beam apex out of the module plane is the load-line displacement $(\Delta)$. This measurement quantifies the critical value of the strain energy release rate, $G_{c}$, which is the material property of adhesion, and represents the energy required for debond extension, given by:

$$
G_{c}=\frac{P_{c}}{2 \tan (\theta / 2)} \frac{\Lambda_{f}}{a_{f}^{2}}
$$

where $P_{c}$ is the critical load plateau at which the debond propogates, $a_{f}$ is a unique value of debond length at the loadline displacement $\Delta_{f}$, and $\theta$ the apex angle of the widthtapered beam.

\section{Sample Preparation}

To evaluate backsheet adhesion, width-tapered beams of $20^{\circ}$ were fabricated from 2 or $3.1 \mathrm{~mm}$ thick acrylic. A handle was incorporated into the beam to provide a location for the attachment of a loading tab whose action could remain at the apex of the beam. After both surfaces were cleaned with isopropyl alcohol, a volume of two-part epoxy (3M 8010) was dispensed and mixed on the beam. The beam was then pressed to the backsheet and weighted. Any excess epoxy was wiped clean prior to full hardening during its room temperature cure. A sharp razor blade was then used to cut through the backsheet around the beam using the straight edge of the beam as a guide. Testing was conducted in a small load frame, placed onto the back of the module, at a constant displacement rate of $10 \mu \mathrm{m} / \mathrm{s}$ while both load and load-line displacement were recorded [4].

To evaluate encapsulant adhesion, beams identical in design to the acrylic beams used for backsheet measurements were 
fabricated from 0.86 and $1.6 \mathrm{~mm}$ thick sheets of high-strength Grade 5 titanium. The modules were prepared by removing the backsheet and encapsulant to expose the backside of the cell, then grinding off the back cell metallization to expose the Si surface. This step is taken to avoid delamination of the back metallization, which typically has low adhesion but is not a concerned point of failure. The Ti beam was then adhered to the back of the cell with a two-part epoxy (3M DP420) and any excess wiped clean prior to hardening during its room temperature cure. A sharp carbide scribe was then used to "cut" the cell around the beam followed by a razor blade to cut the encapsulant through to the front sheet of glass. Testing was similarly conducted in a small load frame, placed onto the back of the module, at a constant displacement rate of $10 \mu \mathrm{m} / \mathrm{s}$ while both load and load-line displacement were recorded.

Both backsheet and encapsulant measurements were repeated at least three times per module and the adhesion values reported are the weighted mean and it's uncertainty.

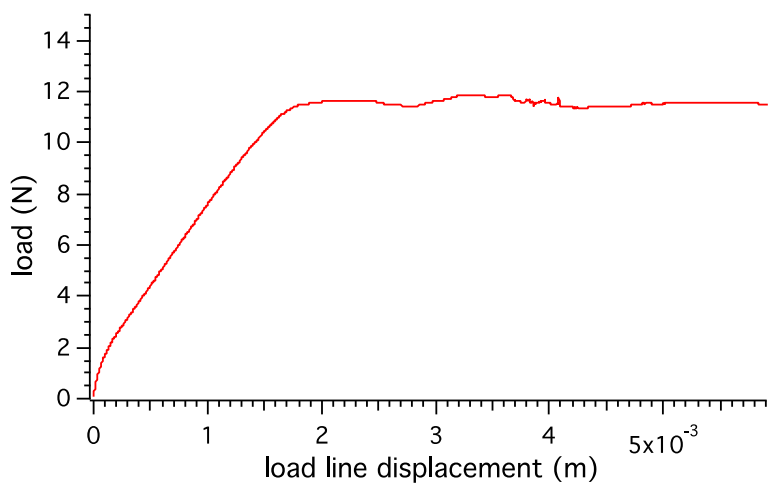

Fig 1. Load vs. displacement response from a width-tapered cantilever beam measurement of backsheet adhesion.

\section{RESULTS AND OBSERVATIONS}

A representative load-displacement curve from the widthtapered beam measurement of backsheet adhesion (Arco Solar, Mexico City, 26-years) is presented in Fig. 1. The critical load plateau, $P_{c}$, for this measurement is $\sim 11.5 \mathrm{~N}$, the final load-line displacement, $\Delta_{f}=5.9 \mathrm{~mm}$ (from plot) and final debond length $a_{f}=57.9 \mathrm{~mm}$ (measured from sample). According to Eq. (1) the critical debond energy, $G_{c}$, or adhesion of this interface is $58.2 \pm 0.6 \mathrm{~J} / \mathrm{m}^{2}$ and the debond was observed to occur between the outer PVF and PET interface. Similar measurements and observations for all modules and interfaces are presented in Table I (c). A variety of backsheet structures were encountered. Typically, backsheet delamination occurred between an outer white film and an inner, or mid-, layer of a clear film. No chemical analyses were performed to positively identify these layers, thus they are only assumed to be a generic fluorinated polymer and a polyester layer, and therefore denoted as PVF and PET, respectively in Table I (c).
Representative images of front encapsulant delamination are presented in Fig. 2. In rare instances as illustrated in Fig. 2 (a), the delamination presented in such a way that adhesion could be directly measured at the pre-existing delamination front (Mobil Solar, Sacramento CA, 27 years). In most other modules obtained, front encapsulant delamination presented in discrete areas around the interconnect ribbons, Fig. 2 (b).
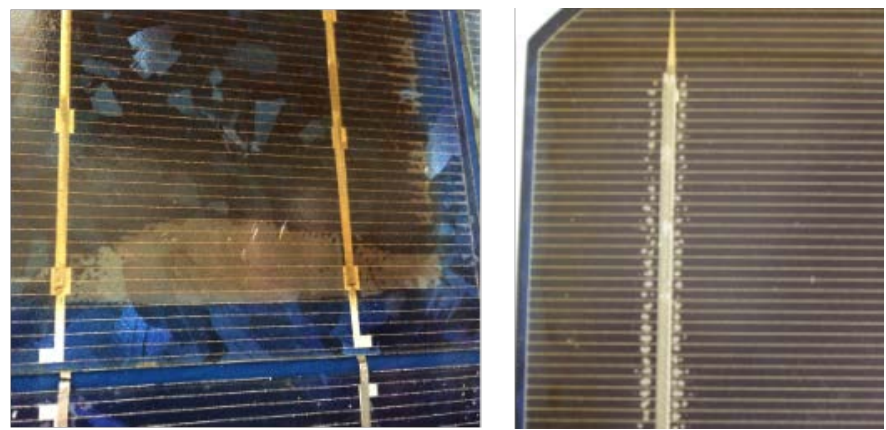

Fig 2. Optical images of modules exhibiting pre-existing encapsulant delamination. a) Left, Mobil Solar, Sacramento CA, 27 years and b) Arco Solar, Mexico City, 26 years.

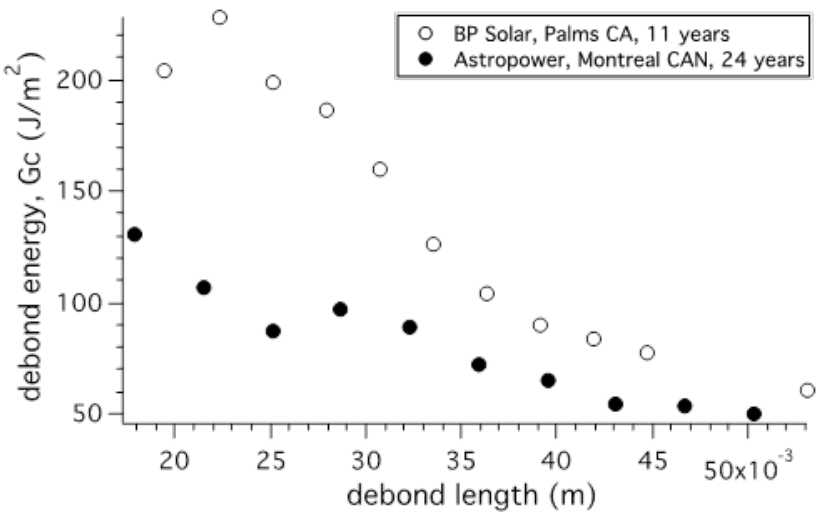

Fig 3. Discrete measures of encapsulant debond energy as a function of debond length.

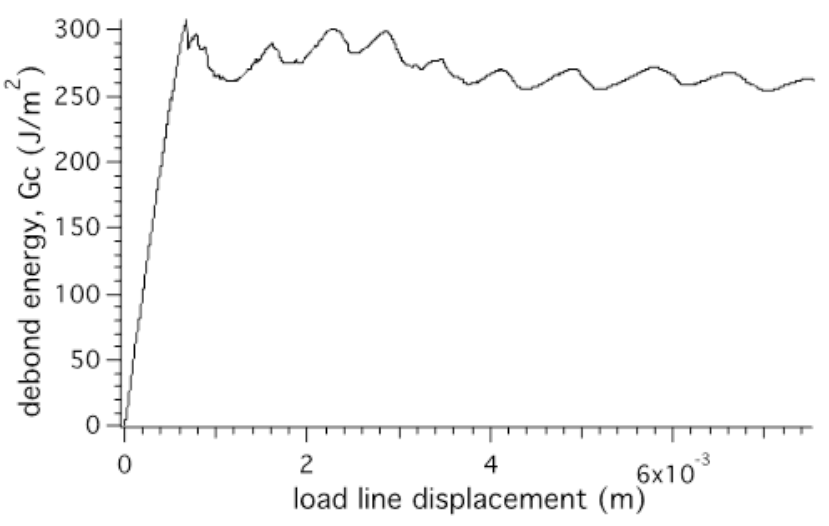

Fig 4. Continuous measure of encapsulant/ glass adhesion.

In these cases the measurement was made away from the preexisting delamination and therefore likely represents an area of higher adhesion and will yield a more conservative estimate of the threshold value for reliability. In one module (BP Solar, Palms CA, 11 years) encapsulant measurements were made 
both at and away from a pre-existing debond front resulting in measurements of $67 \pm 17$ and $233 \pm 49 \mathrm{~J} / \mathrm{m}^{2}$, respectively.

Because the delamination front may be visualized through the module front glass as the measurement progresses, it is possible to also make discrete calculations of adhesion as a function of distance into the cell by evaluating $\mathrm{Eq}$ (1) for periodic measurements of debond length, Fig 3. On most modules without signs of pre-existing delamination, there was little measured variation of adhesion as the measurement progressed. However, when the adhesion levels were low on modules that did exhibit pre-existing delamination, the adhesion was found to decrease as the measurement progressed into the interior of the cell.

When the plateau load is relatively constant, a continuous measure of adhesion may be inferred from the load displacement response by evaluating Eq (1) at every point with the final measurement of debond length. This measurement for one module (Kyocera, unknown deployment) is presented in Fig. 4. The oscillation in debond energy (adhesion) corresponds with the debond front moving past the gridlines as it progresses across the cell. Since the delamination in this module occurred at the glass/ encapsulant interface, this variation is likely due to the changing thickness of the encapsulant. When the encapsulant layer is thicker between the gridlines it may consume more energy during the delamination process thus resulting in a higher measurement of $G_{c}$.

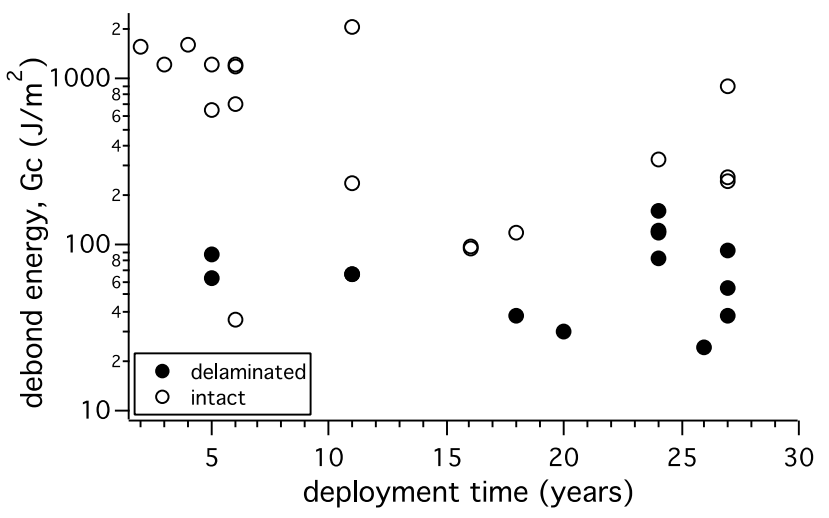

Fig 5. Encapsulant adhesion of the surveyed module exhibiting no preexisting signs of delamination (open symbols) and with pre-existing delaminated areas (closed symbols).

A summary of all encapsulant adhesion measurements is presented in Fig. 5 against module deployment time. Closed symbols represent those modules that exhibited any form of front encapsulant delamination (cell/ encapsulant or glass/ encapsulant) upon initial inspection and open symbols modules with no signs of encapsulant delamination. It is obvious that module deployment time alone is not a perfect indicator of its encapsulant adhesion level. Other factors such as encapsulant material type and formulation, module size and character, processing and quality, and deployment environment and conditions are ultimately much more responsible for both the initial and present adhesion value. However, the level of adhesion required to prevent delamination should be independent of these factors save, to some extent, module size, design and deployment conditions.

While all thirteen instances of pre-existing encapsulant delamination are observed in modules with adhesion levels below $\sim 160 \mathrm{~J} / \mathrm{m}^{2}$, there were also four modules measured with similarly low adhesion values $\left(<120 \mathrm{~J} / \mathrm{m}^{2}\right)$ that did not exhibit delamination. Of these four modules, one was never deployed outdoors (Siemens, Tempe AZ, 18 years) and the remaining three were all characterized to contain relatively thin cells when compared to the older vintage modules that exhibited similar adhesion values yet pre-existing delamination $(\sim 200$ vs. $400 \mu \mathrm{m})$. It is reasonable to expect that a thicker, and therefore stiffer, cell could induce a larger driving force for delamination (out-of-plane stress at this interface) thereby effectively lowering the adhesion threshold for more modern modules with thinner cells to below $35 \mathrm{~J} / \mathrm{m}^{2}$. This is less than $2 \%$ of the initial encapsulant adhesion characterized in modern, quality EVA systems.

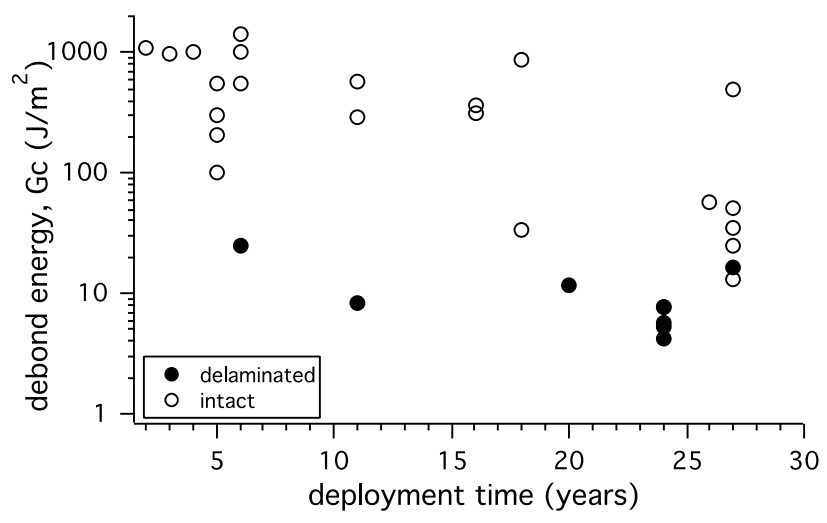

Fig 6. Backsheet adhesion of the surveyed module exhibiting no signs of delamination (open symbols) and with preexisting delaminated areas within the backsheet structure (closed symbols).

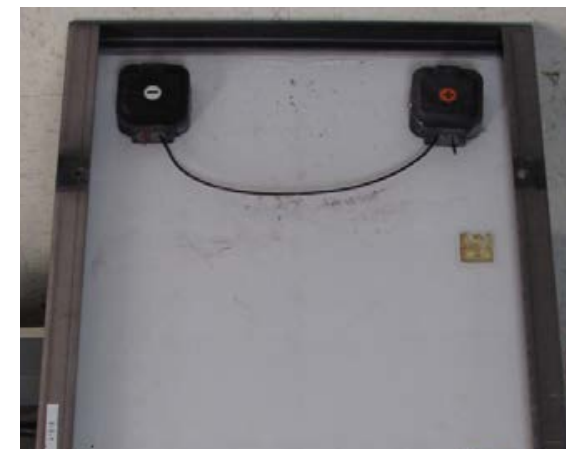

Fig 7. Pre-existing partially delaminated backsheet (Astropower, Montreal CAN, 24 years)

A similar plot of backsheet adhesion against module deployment time is presented in Fig. 6. Modules that exhibited pre-existing delamination typically had a large delamination front across which the backsheet was still intact, 
Fig. 7. This character allowed for the adhesion measurements to be made at this front. All modules measured to have backsheet adhesion less than $12 \mathrm{~J} / \mathrm{m}^{2}$ (seven) exhibited signs of pre-existing delamination. All of these were also more modern backsheet laminate structures that delaminated at the outer PET/ PVF interface. Four additional modules (Sharp Solar, Phoenix AZ, 6 years; Sharp Solar, Denver CO, 11 years; Kyocera; Mobil Solar, Sacramento CA 27 years), which also exhibited pre-existing backsheet delamination, were also characterized. It was found that in all of these modules the failed interface was not truly within the backsheet structure, Table I (c). In the remaining nine modules characterized, only a lower limit of backsheet adhesion may be reported. In each of these cases the adhesion of the backsheet structure was so high that delamination occurred at a lower interface. While we have purposefully sought out modules with degraded adhesion, these truncated measurements demonstrate that these interfaces are capable of retaining a high level of this material property even following a 27-year deployment.

\section{CONCLUSIONS}

This study has introduced our initial effort to quantify a threshold value of both encapsulant and backsheet adhesion. This threshold value should be considered the very minimum required to ensure delamination does not occur at the interfaces of these PV module laminate materials while in service. For encapsulants, this initial threshold $\sim 160 \mathrm{~J} / \mathrm{m}^{2}$ and for backsheet structures $\sim 10 \mathrm{~J} / \mathrm{m}^{2}$.

Our expectation is that these threshold values of adhesion will continue to evolve, and be refined, as the PV community adopts the width-tapered beam method and the population of characterized modules continues to grow. A key aspect to consider while refining these values will be the balance between modules with long service histories and relevant material systems. Furthermore, as demonstrated in this study with the older modules with thicker cells, some specific module characteristics will influence the threshold value. Therefore the "threshold value" should always be a conservative estimation of this property and even be assigned an appropriate safety factor.
Finally, this method of quantifying adhesion and the evolving threshold values should be used to develop accelerated and lifetime tests. When access to the identical material system characterized on a deployed module is available, it may be used to determine an accurate physical degradation model by correlating a corresponding loss in adhesion. Additionally, the evolving threshold value of adhesion may be used as a limit below which this material property may not fall through an accelerated exposure.

\section{REFERENCES}

[1] J. Tracy, N. Bosco, and R. H. Dauskardt, "Evaluation of Encapsulant Adhesion to Surface Metallization of Photovoltaic Cells," in Submitted to IEEE 44th Photovoltaic Specialist Conference (PVSC), Washington D.C., 2017.

[2] J. Tracy, N. Bosco, F. D. Novoa, and R. H. Dauskardt, "Encapsulant and Backsheet Adhesion Metrology for Photovoltaic Modules," Submitted to Progress in Photovoltaics, 2016.

[3] N. Bosco, J. Tracy, R. H. Dauskardt, and S. Kurtz, "Development and First Results of the WidthTapered Beam Method for Adhesion Testing of Photovoltaic Material Systems," presented at the IEEE Photovoltaic Specialist Conference, Portland, OR, 2016.

[4] N. Bosco. (2016). Width-Tapered Cantilever Beam Technique. Available: https://youtu.be/q19li68J60c?list=PLmIn8Hncs7bFpF FBpUQnKXzzx54wucPp1

[5] F. D. Novoa, D. C. Miller, and R. H. Dauskardt, "Debonding Kinetics of Photovoltaic Encapsulation in Moist Environments," Progress in Photovoltaics: Research and Applications, vol. 24, pp. 183-194, 2016.

[6] F. D. Novoa, D. C. Miller, and R. H. Dauskardt, "Environmental mechanisms of debonding in photovoltaic backsheets," Solar Energy Materials and Solar Cells, vol. 120, Part A, pp. 87-93, 1// 2014. 
a

\begin{tabular}{|c|c|c|c|c|}
\hline module & manufacturer & model & deployment location & deployment time \\
\hline 1 & Kyocera & LA361G51S & & \\
\hline 2 & manufacturer $A$ & $x$ & Flagstaff, $\mathbf{A Z}$ & 2 years on sun \\
\hline 3 & \multirow{2}{*}{ manufacturer B } & \multirow{2}{*}{$\mathbf{Y}$} & Tonopah, AZ & 3 years on sun \\
\hline 4 & & & Thailand & 4 years on sun \\
\hline 5 & \multirow{3}{*}{ Astropomer } & & \multirow{3}{*}{ Montreal, CAN } & 5 years on sun \\
\hline 6 & & & & 5 years on-sun \\
\hline 7 & & & & 5 years on-sun \\
\hline 8 & \multirow{3}{*}{ manufacturer B } & \multirow{3}{*}{$\mathbf{Y}$} & Rome, IT & 5 years on-sun \\
\hline 9 & & & Bergamo, IT & 6 years on-sun \\
\hline 10 & & & & 6 years stored \\
\hline 11 & BP Solar & BP71801N & Argenbuhl, DE & 6 years on sun \\
\hline 12 & Sharp Solar & NT-175U1 & Phoenix, AZ & 6 years on sun \\
\hline 13 & BP Solar & Sxisos & Palms, CA & 11 years on sun \\
\hline 14 & BP Solar & BP3125U & Perrysburg, $\mathrm{OH}$ & 11 years on-sun \\
\hline 15 & Sharp Solar & NE-170U1 & Demver, $C O$ & 11 years on sun \\
\hline \begin{tabular}{|l|}
16 \\
17
\end{tabular} & Siemens & M55 & Golden, CO & 16 years on sun \\
\hline 18 & \multirow{2}{*}{ Siemens } & SMS4 & \multirow{2}{*}{ Tempe, AZ } & 18 yrs stored \\
\hline 19 & & M55 & & 18 years on-sun \\
\hline 20 & \multirow{6}{*}{ Astropower } & & \multirow{6}{*}{ Montreal, CAN } & 20 years on sun \\
\hline 21 & & & & 24 years on-sun \\
\hline 22 & & & & 24 years on-sun \\
\hline 23 & & & & 24 years on-sun \\
\hline 24 & & & & 24 years on-sun \\
\hline 25 & & & & 24 years on sun \\
\hline 26 & Arco Solar & M75 & Mexico Gity, MX & 26 years on-sun \\
\hline 27 & \multirow{2}{*}{ Arco Solar } & \multirow{2}{*}{ M52-S } & \multirow{6}{*}{ Sacramento, CA } & 27 years on-sun \\
\hline 28 & & & & 27 years stored \\
\hline 29 & Mobil Solar & JPL block V & & 27 years on sun \\
\hline 30 & Sobarex & & & 27 years on sun \\
\hline 31 & \multirow{2}{*}{ Arco Solar } & \multirow{2}{*}{ M524 } & & 27 years on-sun \\
\hline 32 & & & & 27 years on sun \\
\hline
\end{tabular}

b

encapsulant backsheet

debamination delamination

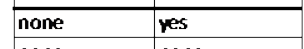

\begin{tabular}{|l|l}
\hline none & none \\
\hline none &
\end{tabular}

\begin{tabular}{|l|l|}
\hline none & none \\
\hline
\end{tabular}

\begin{tabular}{|l|l|}
\hline none & none \\
\hline
\end{tabular}

\begin{tabular}{|l|l}
\hline yes & none \\
\hline
\end{tabular}

\begin{tabular}{|l|l}
\hline yes & none \\
\hline
\end{tabular}

\begin{tabular}{|l|l}
\hline none & none \\
\hline none
\end{tabular}

\begin{tabular}{|l|l|}
\hline none & none \\
\hline
\end{tabular}

\begin{tabular}{|l|l|}
\hline none & none \\
\hline
\end{tabular}

\begin{tabular}{|l|l|}
\hline none & none \\
\hline
\end{tabular}

\begin{tabular}{|l|l|}
\hline none & none \\
\hline
\end{tabular}

\begin{tabular}{l|l} 
none & res \\
\hline
\end{tabular}

\begin{tabular}{|l|l|}
\hline none & \\
\hline ves & \\
\hline
\end{tabular}

\begin{tabular}{l|l} 
none & none
\end{tabular}

none $\quad$ nome

\begin{tabular}{|l|l|}
\hline none & nos \\
\hline
\end{tabular}

\begin{tabular}{|l|l|}
\hline none & none \\
\hline
\end{tabular}

\begin{tabular}{|l|l|}
\hline none & none \\
\hline none
\end{tabular}

\begin{tabular}{|l|l|}
\hline none & none \\
\hline Ves & none \\
\hline
\end{tabular}

\begin{tabular}{|l|l}
\hline yes & none \\
\hline
\end{tabular}

yes yes

\begin{tabular}{l|l} 
yes & res \\
\hline non
\end{tabular}

\begin{tabular}{|l|l}
\hline none & res \\
\hline
\end{tabular}

\begin{tabular}{l|l} 
yes & yes \\
\hline
\end{tabular}

yes yes

\begin{tabular}{|l|l}
\hline yes & res \\
\hline
\end{tabular}

\begin{tabular}{|l|l|}
\hline yes & none \\
\hline yes & none \\
\hline
\end{tabular}

\begin{tabular}{l|l} 
none & none
\end{tabular}

\begin{tabular}{|l|l|}
\hline none & none \\
\hline
\end{tabular}

\begin{tabular}{|l|l|}
\hline Yes & severe \\
\hline
\end{tabular}

\begin{tabular}{|l|l}
\hline yes & none \\
\hline
\end{tabular}

\begin{tabular}{|l|l|}
\hline yes & none \\
\hline none & none \\
\hline
\end{tabular} \begin{tabular}{|l|l|l|l|}
\hline encapsulant & interface & backsheet & interface \\
\hline
\end{tabular}

$G_{\mathrm{c}}\left(\mathrm{J} / \mathrm{m}^{2}\right) \quad \mathrm{G}_{\mathrm{c}}\left(\mathrm{J} / \mathrm{m}^{2}\right)$

\begin{tabular}{|l|l|l|l}
\hline $270.0 \pm 12$ & gtass & $98.9 \pm 1.4$ & outer foil \\
\hline $1550 \pm 21$ & cell & $>1100^{1}$ & withincell
\end{tabular}

\begin{tabular}{l|l|l|l|}
\hline $1550 \pm 21$ & cell & $>1100^{1}$ & within cell back metal
\end{tabular}

\begin{tabular}{l|l|l|l}
$1240+19$ & cell & $>960^{\mathbf{1}}$ & within cell back metal
\end{tabular}

\begin{tabular}{|l|l|l|l}
\hline $1620 \pm 15$ & cell & $>1000^{\mathbf{1}}$ & within cell back metal
\end{tabular}

\begin{tabular}{l|l|l|l}
$63.3 \pm 2.1$ & cell & $>300^{1}$ & front encapsulant
\end{tabular}

\begin{tabular}{|l|l|l|l}
\hline $87.0+2.3$ & cell & $556 \pm 5.7$ & outer PET/PVF \\
\hline
\end{tabular}

\begin{tabular}{|l|l|l|l|}
\hline $651 \pm 14$ & ghass & $205 \pm 6.4$ & back encapsulant/PVF \\
\hline $1210 \pm 27$ & Cefl & $101 \pm 23$ & outer PET/PVF \\
\hline
\end{tabular}

\begin{tabular}{l|l|l|l}
\hline $1210 \pm 2.7$ & cell & $101+23$ & outer PET/PVF
\end{tabular}

\begin{tabular}{l|l|l|l}
$1180+7.0$ & cell & $>1400^{1}$ & within cell back metal
\end{tabular}

\begin{tabular}{|l|l|l|l}
\hline $1210+29$ & glass & $>1000^{1}$ & back encapsulant/cell
\end{tabular}

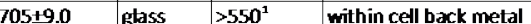

\begin{tabular}{|l|l|l|l|}
\hline $34.9+2.2$ & ghass & $\mathbf{2 4 . 7 \pm 2 . 2}$ & within cell back metal
\end{tabular}

$67.0 \pm 17 \quad$ cell

\begin{tabular}{|l|l|l|l}
\hline $233 \pm 49$ & cell & $288 \pm 45$ & back encapsulant/cell
\end{tabular}

\begin{tabular}{l|l|l|l}
\hline $2070 \pm 10$ & cell & $>570^{\mathbf{1}}$ & back encapsulant/cell
\end{tabular}

\begin{tabular}{|l|l|l|l|}
\hline $67.1+7.7$ & gtass & $\mathbf{8 . 3 0}+0.5$ & within cell back metal
\end{tabular}

\begin{tabular}{|l|l|l|l|}
\hline $95.0 \pm 2.9$ & cell & $312+2.8$ & outer PET/PVF
\end{tabular}

\begin{tabular}{|l|l|l|l}
$\mathbf{9 8 . 7}+3.5$ & cell & $\mathbf{3 6 5}+28$ & outer PET/PVF
\end{tabular}

\begin{tabular}{|l|l|l|l}
\hline $118+5.4$ & cell & $\mathbf{8 6 7} \pm 26$ & outer PET/PVF
\end{tabular}

\begin{tabular}{|l|l|l|l|}
\hline $\mathbf{1 1 8 . 5 . 4}$ & cell & $\mathbf{8 6} 126$ & outer PEI/PVF \\
\hline $\mathbf{3 7 . 2 + 1 . 6}$ & cell & $\mathbf{3 3 . 7 \pm 0 . 5 1}$ & outer PET/PVF
\end{tabular}

\begin{tabular}{l|l|l|l|l}
$30.4+1.5$ & cell & $\mathbf{1 1 . 5}+0.52$ & outer $\mathrm{PET} / \mathrm{PVF}$
\end{tabular}

\begin{tabular}{|l|l|l|l|l}
\hline $159 \pm 8.6$ & cell & $7.60 \pm 0.17$ & outer PET/PVF
\end{tabular}

\begin{tabular}{|l|l|l|l|}
\hline $328 \pm 6.1$ & cell & $7.63 \pm 0.15$ & outer PET/PVF \\
\hline $83.3 \pm 3.6$ & cell & $4.21 \pm 0.57$ & out PET/PVF
\end{tabular}

\begin{tabular}{|l|l|l|l}
\hline $83.3+3.6$ & cell & $4.21+0.57$ & outer PET/PVF
\end{tabular}

\begin{tabular}{|l|l|l|l}
\hline $122+11$ & cell & $\mathbf{5 . 3 7 + 0 . 1 3}$ outer PET/PV \\
\hline
\end{tabular}

\begin{tabular}{|l|l|l|l}
\hline $120.0+11$ & ghass & $5.75+0.31$ & outer PET/PVF
\end{tabular}

\begin{tabular}{|l|l|l|l|}
\hline $24.2+1.1$ & cell & $58.2+0.62$ & inner PET/PVF \\
\hline $245+28$ & (1) & $25.2+2.2$ & Onter PET/PVF \\
\hline
\end{tabular}

\begin{tabular}{|l|l|l|l}
\hline $245+28$ & gtass & $25.2+2.2$ & outer PET/PVF \\
\hline $86+120$ & cell & $12.9+0.81$ & outer PET/PVF
\end{tabular}

\begin{tabular}{l|l|l|l}
$896+120$ & cell & $12.9+0.81$ & outer PET/PVF
\end{tabular}

\begin{tabular}{|l|l|l|l|}
\hline $\mathbf{8 4 . 6 \pm 5 . 0}$ & ghass & $16.7 \pm 5.7$ & back encapsulant/ PET \\
\hline
\end{tabular}

\begin{tabular}{|l|l|l|l|}
\hline $37.1+1.6$ & gtass & $>500^{1}$ & front encapsulant
\end{tabular}

\begin{tabular}{l|l|l|l}
$91.3 \pm 5.5$ & glass & $35.0 \pm 0.53$ & outer PET/PV
\end{tabular}

\begin{tabular}{|l|l|l|l}
\hline $\mathbf{2 5 5} \pm 34$ & ghass & $\mathbf{5 0 . 4 \pm 1 3}$ & outer PET/PV \\
\hline
\end{tabular}

Table I. Tabulated list of a) module and deployment details, b) pre-existing observations and c) results of adhesion measurements. Omitted module details were not recoverable. 